\title{
Assessment Within Educational Settings: The Creative Process
}

\author{
Valgeirsdóttir, Dagný; Onarheim, Balder
}

Published in:

Proceedings of the 9th Global Conference on Creative Engagements: Thinking with Children

Publication date:

2014

Link back to DTU Orbit

Citation (APA):

Valgeirsdóttir, D., \& Onarheim, B. (2014). Assessment Within Educational Settings: The Creative Process. In Proceedings of the 9th Global Conference on Creative Engagements: Thinking with Children

\section{General rights}

Copyright and moral rights for the publications made accessible in the public portal are retained by the authors and/or other copyright owners and it is a condition of accessing publications that users recognise and abide by the legal requirements associated with these rights.

- Users may download and print one copy of any publication from the public portal for the purpose of private study or research.

- You may not further distribute the material or use it for any profit-making activity or commercial gain

- You may freely distribute the URL identifying the publication in the public portal

If you believe that this document breaches copyright please contact us providing details, and we will remove access to the work immediately and investigate your claim. 


\title{
Assessment Within Educational Settings: The Creative Process
}

\author{
Dagný Valgeirsdóttir \\ Balder Onarheim
}

\begin{abstract}
Despite existing enthusiasm and evidence for the effectiveness of innovative forms of educating and learning changing practices in educational systems is challenging as centuries old practices are ingrained in political and organizational structures that naturally resist change. This resistance to change is relevant to the topic of assessment within educational settings as methods for assessing student output through exams are still pre-dominant and innovative ways of assessing are rare. This chapter will focus on assessment of creativity and how it is applicable within an educational setting with an emphasis on assessing not only the student output but the creative process as a whole. The creative process is a phenomenon that every student goes through during his or hers education, whether it is identified as such or not. Significance should be attributed to efforts made by students throughout their creative processes rather than only focusing on their final output, as a creative process does not guarantee a creative output. Students and teachers alike can learn and benefit from considering the creative process, and an assessment method appropriate to fulfil the task of assessing the process will be introduced and its applicability portrayed.
\end{abstract}

Key Words: Creativity, learning, education, assessment, creative assessment, creative process, consensual assessment technique, CAT.

$* * * * *$

\section{Introduction}

In modern educational systems, the assessment of students is an increasingly discussed topic, especially in relation to increasing demands on schools to produce 'creative and innovative students'. This is an interesting paradox: while most assessment in modern schools is based on exams evaluating the final output, it is acknowledged from creativity research that a creative process does not always produce something creative. This paradox should be familiar to any teacher, the pain of having to fail a student that evidently went through a highly creative process that failed, but the system only allows for giving the final grade based on the product. As a teacher, you know that every time you do that, the student's believe in creativity decreases. Thus, this chapter focuses on assessment of creativity, arguing that assessing the output from creative processes alone is not 
sufficient for nurturing creativity in educational settings. It is argued that the creative process must also be taken into account, as a creative process cannot guarantee a creative output and failed attempts should therefore be valued. It is suggested how well established creative product assessment tools could potentially be utilized for assessing the creative learning process, as a step towards acknowledging creativity in school settings.

Innovation and entrepreneurship are critical concepts within higher educational programs, enabling students to learn how to creatively approach and solve problems. ${ }^{1}$ Creativity can be assumed to be the necessary component for both concepts and is normally defined as the process of developing new and original ideas that are somehow appropriate for a specific purpose and thereby bringing value. ${ }^{2}$ However, creativity is neither only a narrow concept describing how new ideas originate on an individual level, nor is it a mysterious attribute that only a lucky few possess, in deed it is demonstrated how trait creativity can be trained and nurtured in students. ${ }^{3}$ Moreover, creativity research is becoming an increasingly broad field of study interested in e.g. organizational creativity and the components of the creative process ${ }^{4}$ as well as e.g. creativity and learning ${ }^{5}$, portraying the importance of creativity on a variety of societal levels.

The concepts of creativity, innovation and entrepreneurship are often used interchangeably, and here it will be argued that the concepts are commonly confused together as they are all associated with originality. It is theorized that creativity can exist without innovation and entrepreneurship, while creativity is an important driver for the other two. As innovation and entrepreneurship are seen as serving important roles within society it is of great importance to prepare students from the early stages of their education to maintain, activate and nurture their creative abilities to enable innovativeness and entrepreneurial ambitions. Unfortunately, studies are suggesting the opposite, namely that children are 'trained out of their creativity' as they grow up. Before moving on to discussing assessment it is useful to first review what creativity is, how it is important for individual learning and how schooling might in fact reduce creativity.

\section{Individual Learning and Creativity}

Creativity is increasingly being assumed to play an important role in education, as studies show that children are highly creative at the age when they enter school. Some components of educational systems could be viewed as inhibiting creative potential, e.g. learning processes, teaching skills, motivational methods etc. ${ }^{6}$ Moreover, it has been shown that expecting a creative output can negatively influence the creative process. ${ }^{7}$ On an individual level of creativity it is a widespread misconception that it is solely based on internal factors, and external factors such as education, society and extrinsic motivation are commonly overlooked. ${ }^{8}$ In this elaborate review concerning learning and creativity Selvi points out that it is of importance to acknowledge that internal and external factors 
do in fact affect each other, and combined they strongly influence individual creativity. In terms of learning and creativity, individual learning is a complex part of creativity and both concepts are components of basic human experience as individuals constantly learn from their experiences (e.g. failure and/or success), feelings, imagination and society (e.g. environment). However, many of the external factors that individuals come in touch with can act as barriers to creative potential, educational systems being one of them. Time constraints, assessment methods, teacher competences (or preferences), school leadership etc. can all contribute to reducing creativity. ${ }^{9}$ One important factor to take into account is that opinions about 'who can learn what' are very persistent in educational systems although there is substantial body of research supporting that the ability to learn can be taught. ${ }^{10}$ Creativity is an important factor in that context as it is a way of learning and achieving things in a way that enables individuals to be less afraid of failure, be more independent and willing to take risks, which incidentally are all personality traits that research has shown teachers to dislike. ${ }^{11}$ Furthermore it is an integral part of education that intelligence and 'exam solving skills' are the fundamentals of education, i.e. the final product; the outcome of an exam. This disregards the efforts that have been made by the individual student in the process of education, and some psychologists point out the need to change this setting, to rather attribute failure and success to efforts made than abilities to solve tests ${ }^{12}$. This suggestion leads this chapter towards defining creative assessment as well as the creative process.

\section{Assessing the Creative Process}

Throughout the lifespan of creativity research it has been of interest to assess the concept of creativity, to fathom what it is and what affect it has on various aspects of life. This is especially true as creativity is fundamental to human nature and is an aspect that enriches lives. ${ }^{13}$ Here it is held that creative assessment is the prerequisite of any creativity analysis, which contributes to its understanding and in an educational setting consequently enables the process of describing creative practice there within. Identifying appropriate ways of accomplishing creative assessment within educational settings is therefore argued to be of high relevance to the topic of creativity and education.

In order to assess creativity it is necessary to have the right tools to do so, which has resulted in a dyad of different creative assessment tools constructed for various different purposes. Those purposes can broadly be classified into four different categories built on the traditional 'four P's of creativity': Person, product, process and press. ${ }^{14}$ In this chapter the focus is put on the two categories of product and process, as to our knowledge there have not yet been any specific assessment tools designed to assess the creative process. In fact, in classical psychological studies of creativity, the assessment tools have even been criticized for not considering the creative process. The purpose of the empirical work 
referred to below was to assess whether such tests are as product focused as they are criticized for being, and whether knowledge about the process can impact the assessment of the output. Establishing that product-focused assessment methods are applicable to assessing the creative process would enable use of well-developed creative assessment methods, e.g. Consensual Assessment Technique (CAT), ${ }^{15}$ in terms of creative process assessment within educational systems.

Due to the lack of assessment tools applicable to assess the creative process it was specifically tested in one study, i.e. whether a product creativity assessment method could be applied to assess the creative process. ${ }^{16}$ There it was investigated whether participants were able to use CAT to reliably assess the creativity level of the process just as well as the product, in addition to exploring the correlations between 1) creativity ratings when being presented only with the creative process and 2) creativity ratings when only presented with the creative product. As a result it was clear that participants were able to assess the process equally well as the products, and the ratings of process correlated with the ones for the products, demonstrating that product creativity assessment methods can in deed be applied when assessing the creative process. ${ }^{17}$

In this particular study CAT was applied, which is a subjective creativity assessment method that has been used for over three decades to assess the creativity level of products and ideas. An assumption is made when applying the CAT that objects can only be creative if the appropriate judges find them creative, specifying appropriate judges as those who have knowledge within the domain from where the products or ideas originate. The judges make independent subjective assessments of the items to be rated, eliminating the need for definitive criteria and making it more like an everyday assessment within specific domains. ${ }^{18}$ This provides the method with the quality its known for, i.e. the judges are not provided with creativity as a specified or predefined attribute thus eliminating the bias that arises when creators of assessment tools provide their own specific definition of what they feel creativity entails. The interesting finding that is revealed when applying CAT is that despite the judges not being provided with predetermined criteria there is usually a high level of agreement within the judgements, proving that even though creativity is hard to define, it is certainly something that people can recognize and agree upon ${ }^{19}$.

While the study shows a relationship between creative process and product, it does not reveal the nature of the relationship. Is the process creative because the product is, is perception of creativity in the output based on an assumption about the process, or is the process creative and therefore produces a creative output? As mentioned above it is an acknowledged attribute with creativity that a creative process does not always result in a creative output, and it is therefore of interest to investigate whether knowledge of the creative process could amplify creativity ratings for products. If so, it would point to the fact that the process is somehow counted in, consciously or unconsciously, in creativity assessment of products. In a 
recent study we therefore applied CAT to investigate whether ways of presenting the creative process would have an impact on creativity assessment of products. ${ }^{20}$ Specifically it was investigated whether informing participants that the creative process behind a product was complex would amplify creativity ratings. It was hypothesized that storytelling about that particular detail of the process would influence perceptions of the creativity level of products. Interestingly the results showed that simply stating that the process was complex did not influence creativity ratings showing no significant difference between ratings of product and process conditions. ${ }^{21}$ However, an interesting conclusion was drawn from the results relating to the topic of storytelling and narratives, which further revealed how communicating about the creative process can contribute to the assessment of its output. This will be elaborated on, and related to creative assessment within education, in the next section.

\section{Applying Creative Assessment within Education}

In the beginning of this chapter the question was raised of how students can be fairly assessed and it was proposed that an exam is perhaps not the most optimal way to assess the output of student's creative processes. The recent study by Valgeirsdóttir, Onarheim and Gabrielsen revealed that simple communications about the creative process do not influence creativity ratings, however, it was held that a more elaborate storytelling about it should theoretically have an impact. ${ }^{22}$ This does call for further research, however, the same general assumption will be made here. Just as creativity, storytelling is a communications form that is deeply rooted in human nature. ${ }^{23}$ Storytelling has been used as a way to communicate ever since the human race started to be able to communicate, as stories were e.g. used to inform others of how food was hunted as well as how and where to avoid danger. This form is associated with giving meaning to experiences and with motivating engagement. ${ }^{24}$

Relating these findings back to assessment within education it should again be affirmed that some researchers are suggesting that student assessment within some forms of education should be done with concern to efforts made throughout the teaching period, rather than abilities to solve final tests. ${ }^{25}$ Here it will be held that there is a relationship between the two concepts, i.e. efforts and creative process, as it will be argued that the efforts students make are in deed part of what can be referred to as their creative process. Due to the indication of the results it is argued here that an elaborate presentation, or storytelling, produced by the student, describing the creative process throughout the course, is needed to communicate about motivation and involvement, which is believed to be necessary in order to make a fair creativity assessment. ${ }^{26}$

Because objective assessments are argued to be hard to obtain in school settings it should be considered to apply a more subjective manner of assessing the output of students, i.e. the reports made by the students, which would be his or hers 
storytelling about involvement, motivation and the general creative process that he or she went through. Thus it is concluded here that CAT could very well be applicable within an educational setting precisely because of its subjective approach. Teachers would be asked to assess the student's description of his or hers creative processes to measure both its creativity level as well as getting an insight into the student's efforts and involvement. By including more teachers in the assessment of individual students the subjectivity of what is creative, as well as the bias that possibly arises when merely the teacher that has a relationship with the student performs the assessment, could thereby be reduced. Hence, in accordance with CAT, it will be suggested that approximately five to six teachers assess the student output. Including a multiple number of teachers would enable a fair assessment for each student, which would not necessarily be based on individual perceptions of creativity or teacher-student relationships, but rather an anonymous assessment of the student's creative process. Selvi proposed that some attributes of students, which are associated with being creative, are not attributes that teachers seem to like in students, in fact they rather seem to dislike those attributes. ${ }^{27}$ The multiple number of teachers anonymously assessing each student could be a way to minimize that effect as by introducing such a creative assessment of efforts made by students the 'creatives' could be allowed to equally get a fair assessment, which does not judge them for being untraditional in their work methods.

\section{Conclusion}

Because creativity and innovation serve such important roles in society it is of importance to nurture those skills in students from early on. It is a widespread belief that students are being educated out of their creative abilities in the modern school systems, in part because the attributes associated with being creative are frowned upon as well as because the assessment methods in use rely heavily on exam solving skills, rather than motivation to learn. By asking students to reflect on their creative processes throughout the teaching period their involvement might be increased because being aware of the creative process is believed to positively influence trait creativity. ${ }^{28}$

Drawing from this insight some conclusions have been made in relation to the subject of creativity, education and how to fairly assess the creative process as it can be unfair to objectively assess only the output. Storytelling is believed to be a powerful way to communicate, and storytelling about the creative process could be an effective way for students to produce their output to be subjectively assessed by teachers. Because objective assessment methods will be assumed to be unfair where not necessarily one specific output is of importance but rather the efforts made by the student, it is acceptable to apply a subjective assessment method, however, it is necessary to include a multiple number of teachers to acquire a fair assessment. CAT is believed to be a competent tool for that purpose as it relies on 
subjective assessment of judges that possess knowledge within the domain in question. Judges are not provided with predetermined criteria and make their assessments based on their own subjective assumptions about what they consider creative. The creativity assessments of the student's processes proposed here should in the end contribute to their overall assessment for the topic.

It is argued that the benefits from using this approach are at least threefold, first all students get a more equal creative assessment, which would be considered when they get their final assessment, second this has the possibility of engaging and motivating each student greater and third, teachers could probably learn a great deal from being introduced to their student's creative processes, enabling a better learning experience for all parties involved. However, as was touched upon previously, changing practices within established organizations can be troublesome but that should not discourage researchers from further investigating ways of improvement, as is being done here.

\section{Notes}


1 Unger, Darian. "Innovation Commercialization and Licensing in Entrepreneurial Business Education." NCIIA's 17th Annual Conference. . Washington DC: NCIIA, 2013, 1.

2 Stein, Morris I. "Creativity and culture." Journal of Psychology 36 (1953): 31-322.

3 Onarheim, Balder, and Friis-Olivarius, Morten. "Applying the neuroscience of creativity to creativity training." Frontiers in Human Neuroscience 2 (2013): 7-8.

4 Amabile, Teresa M. Creativity in Context. Boulder, Colorado: Westview Press, 1996.

5 Selvi, Kiymet. "Learning and creativity." Edited by A. T. Tymieniecka. Phenomenology of Life from the Animal Soul to the Human Mind (Springer) 2 (2007): 351.

6 Ibid., 355.

7 Amabile, "Creativity in Context", 135-141.

8 Selvi, "Learning and Creativity", 353.

9 Ibid., 355.

${ }^{10}$ Resnick, Lauren B., James P. Spillane, Goldman, Pam and Rangel, Elizabeth S. "Implementing innovation: from visionary models to everyday practice." In The nature of learning: Using research to inspire practice, by H Dumont, D. Istance and F. (Ed.) Benavides, 288. OECD, 2010.

${ }^{11}$ Selvi, "Learning and Creativity", 361.

${ }^{12}$ Resnick et al., "Implementing Innovation", 288.

${ }^{13}$ Clapham, Maria M. "Testing/Measurement/Assessment." In Encyclopedia of Creativity, by M. Runco and S. R. (Eds.) Pritzker, 458. Boston: Academic Press, 2011.

${ }^{14}$ Rhodes, Mel. (1961). An analysis of creativity. The Phi Delta Kappan, 42 (7), (1961): 307.

${ }_{15}$ Amabile, Teresa M. "Social psychology of creativity: A consensual assessment tecnique." Journal of Personality and Social Psychology 43, no. 5 (1982): 997-1013.

${ }^{16}$ Hennessey, Beth A. "The consensual assessment technique: An examination of the relationship between ratings of product and process creativity." Creativity Research Journal 7, no. 2 (1994): 196-197.

${ }^{17}$ Ibid., 197-198.

${ }^{18}$ Amabile, "Social psychology of creativity", 1001-1003.

${ }^{19}$ Hennessey, "The consensual assessment technique", 195.

20 Valgeirsdóttir, Dagný, Balder Onarheim, and Gorm Gabrielsen. "Product Creativity Assessment of Innovations: Considering the Creative Process." International Journal of Design Creativity and Innovation, 2014: Under review.

${ }^{21}$ Ibid.

${ }^{22}$ Valgeirsdóttir, Onarheim and Gabrielsen. "Product Creativity Assessment of Innovations".

${ }^{23}$ Fisher, Walter R. "Narration as a human communication paradign: The case of public moral argument." Communications Monographs 51, no. 1 (1984): 7-8.

${ }^{24}$ Ibid., 8 .

${ }^{25}$ Resnick et al., "Implementing Innovation", 288.

${ }^{26}$ Valgeirsdóttir, Onarheim and Gabrielsen. "Product Creativity Assessment of Innovations".

${ }^{27}$ Selvi, "Learning and Creativity", 361.

${ }^{28}$ Onarheim and Friis-Olivarius, "Applying the neuroscience of creativity", 7-8.

\section{Bibliography}

Amabile, Teresa M. Creativity in Context. Boulder, Colorado: Westview Press, 1996.

Amabile, Teresa M. "Social psychology of creativity: A consensual assessment tecnique." Journal of Personality and Social Psychology 43, no. 5 (1982): 997-1013.

Clapham, Maria M. "Testing/Measurement/Assessment." In Encyclopedia of Creativity, by M. Runco and S. R. (Eds.) Pritzker, 458-464. Boston: Academic Press, 2011.

Fisher, Walter R. "Narration as a human communication paradigm: The case of public moral argument." Communications Monographs 51, no. 1 (1984): 1-22.

Hennessey, Beth A. "The consensual assessment technique: An examination of the relationship between ratings of product and process creativity." Creativity Research Journal 7, no. 2 (1994): 193-208.

Onarheim, Balder, and Morten Friis-Olivarius. "Applying the neuroscience of creativity to creativity training." Frontiers in Human Neuroscience 2 (2013): 1-10. 
Resnick, Lauren B., James P. Spillane, Pam Goldman, and Elizabeth S. Rangel. "Implementing innovation: from visionary models to everyday practice." In The nature of learning: Using research to inspire practice, by H Dumont, D. Istance and F. (Ed.) Benavides, 285-308. OECD, 2010.

Rhodes, Mel. "An analysis of creativity." The Phi Delta Kappan 42, no. 7 (1961): 305-310.

Selvi, Kiymet. "Learning and creativity." Edited by A. T. Tymieniecka. Phenomenology of Life from the Animal Soul to the Human Mind (Springer) 2 (2007): 351-370.

Stein, Morris I. "Creativity and culture." Journal of Psychology 36 (1953): 31-322.

Unger, Darian. "Innovation Commercialization and Licensing in Entrepreneurial Business Education." NCIIA's 17th Annual Conference. Washington DC: NCIIA, 2013. 1-9.

Valgeirsdóttir, Dagný, Balder Onarheim, and Gorm. Gabrielsen. "Product Creativity Assessment of Innovations: Considering the Creative Process." International Journal of Design Creativity and Innovation, 2014: Under review.

Dagný Valgeirsdóttir is a creativity researcher based in Copenhagen. Originally from Iceland, Dagný moved to Denmark to master in communications management, but caught an interest in the topics of learning and creativity and assessment of the creative process and is now preforming empirical studies on various aspects of creative assessment.

Balder Onarheim is an assistant professor at the Technical University of Denmark, where he teaches creativity, innovation and entrepreneurship. After a career as an industrial designer, Balder went on to write a $\mathrm{PhD}$ on 'Creativity under Constraints', and in addition to his interest in constraints as drivers for creativity he is very interested in the topic of creativity training 